\title{
AUMENTO DE PRODUTIVIDADE NA EXECUÇÃO DE FUNDAÇÕES PROFUNDAS PELA INTRODUÇÃO DE INOVAÇÕES - CASO INO//FAST ${ }^{\circledR *}$
}

\section{Resumo}

Willy Ank de Morais ${ }^{1}$ Guilherme Geada Sampaio ${ }^{2}$ Rodrigo Antunes Sampaio ${ }^{3}$ Fabio Pirillo Bueno ${ }^{4}$

Historicamente a execução de fundações profundas com perfis metálicos eram prejudicadas pela falta de sincronia entre as atividades de cravação das vigas e suas emendas. O grande problema é a demora na execução das emendas, tipicamente pelo uso de soldagem com talas, que normalmente leva 1 hora para ser completada. Neste trabalho analisou-se o Caminho Critico (MCC) da operação para incrementar a produtividade na execução de fundações profundas pela adoção de dispositivos, equipamentos e processos de alta produtividade, encabeçados por soldadores qualificados e certificados. Com isso, criou-se o processo INO///FAST ${ }^{\circledR}$, aqui apresentado, que permite obter uma emenda, atendendo plenamente aos preceitos da norma ABNT NBR 6122:1996 ("Projeto e execução de fundações"), em apenas 10 minutos. O processo desenvolvido foi analisado, verificado e comprovado em uso prático por pesquisadores, engenheiros e técnicos.

Palavras-chave: Produtividade; Método do Caminho Crítico; Fundações profundas; Aços estruturais.

\section{INCREASE OF PRODUCTIVITY ON EXECUTION OF DEEP FOUNDATIONS BY THE INTRODUCTION OF INNOVATIONS - INO///FAST CASE}

\section{Abstract}

Historically the execution of deep foundations with metal profiles were affected by the lack of synchronization between the driving (spiking) activity of the beams and its junction. The major concern is with the delay in the implementation of the joints, typically by welding use with splints, which normaly takes 1 hour to be complete. In this work It was analised the Critical Path of operation to boost productivity on execution of deep foundations by the adoption of devices, equipment and high productivity processes, headed by trained and certified welders. Thus, it was created the INO///FAST ${ }^{\mathrm{TM}}$ process, introduced here, that alloys obtaining a joint, which fully complies with the requirements of Brazilian standard NBR 6122:1996 ("Design and construction of foundations"), in just 10 minutes. The developed process was analyzed, verified and proven during practical use by researchers, engineers and technicians.

Keywords: Productivity; Critical Path Method; deep foundations; structural steel.

1 Doutorando, Mestre, Engenheiro e Técnico em Metalurgia e Materiais, Sócio-Diretor da Willy Ank Soluções Metal-Mecânicas, Professor Mestre da UNAERP-Guarujá e Professor Adjunto da Universidade Santa Cecilia (UNISANTA), Santos, SP, Brasil (wmorais@unaerp.br).

2 Técnico em Metalurgia, Inspetor de Soldagem Nível 2 (ASME B31.1), Diretor Comercial, INSPEBRAS, Praia Grande, SP, Brasil (guilherme@inspebras.com.br).

3 Técnico em Metalurgia, Inspetor de Soldagem Nível 2 (AWS), Diretor Técnico, INSPEBRAS, Praia Grande, SP, Brasil (rodrigo@inspebras.com.br).

4 Técnico em Metalurgia, Diretor Operacional, INSPEBRAS, Praia Grande, SP, Brasil (fabio@inspebras.com.br). 


\section{INTRODUÇÃO}

Para a execução de fundações sólidas, executadas em terrenos pouco resistentes e profundos, torna-se necessário a realização de um estaqueamento profundo. Um dos principais métodos de execução de fundações profundas [1] é pelo uso de vigas metálicas, atualmente no aço ASTM A572 Gr.50 [2], e que possuem um comprimento padrão de $12 \mathrm{~m}$. Como estas vigas são cravadas, formando estacas metálicas, em profundidades que ultrapassam o seu comprimento padrão, conforme ilustrado na Figura 1, torna-se necessário promover a sua união. O método mais tradicionalmente empregado é através da soldagem de topo destes perfis complementada pela soldagem de talas [1], conforme exemplificado na Figura 2.

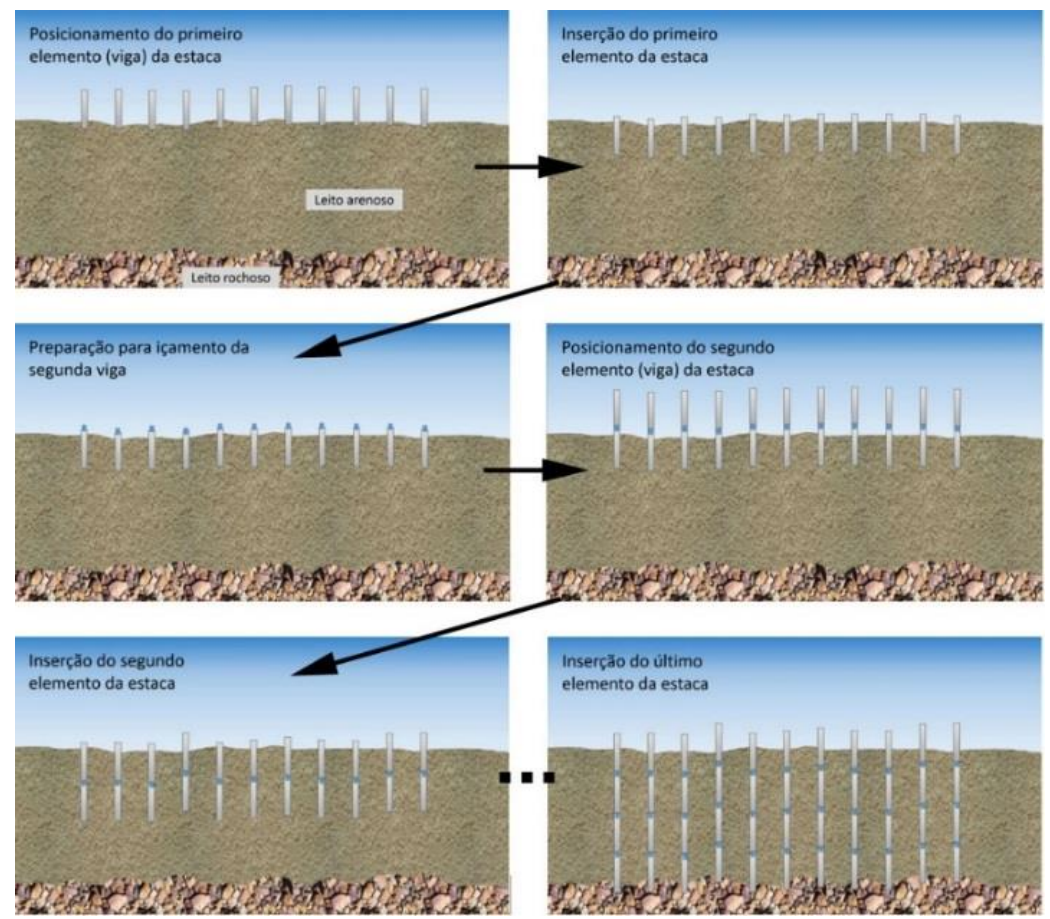

Figura 1. Exemplo de execução de uma sequência de cravação de estacas formadas por quatro perfis estruturais de $12 \mathrm{~m}$.

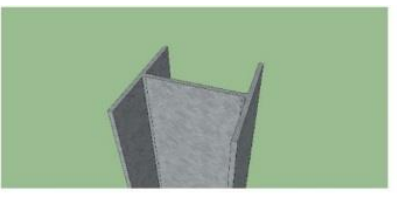

Início: parte superior de uma estaca cravada.

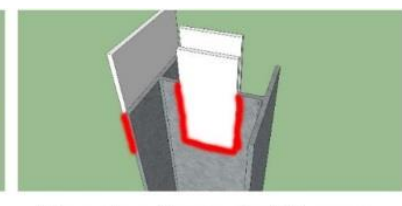

Etapa A: soldagem das talas para colocação da nova viga.

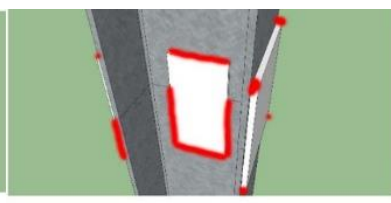

Etapa B: nova viga colocada e ponteamento das talas.

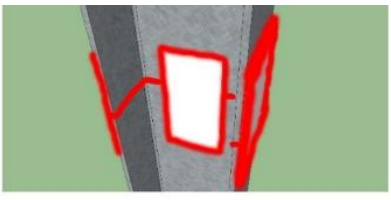

Etapa C: soldagem final das talas e das vigas antes da cravação.

Figura 2. llustração do processo de união de perfis metálicos constituintes de uma estaca de uma fundação profunda.

Como em qualquer atividade industrial, na operação de cravação de estacas objetiva-se a obtenção das seguintes condições durante sua execução: segurança, qualidade, rapidez, custo competitivo e eficiência. $O$ atraso nas atividades de cravação das estacas impacta diretamente o cronograma de toda obra civil e a disponibilidade de espaços produtivos (greenfield ou brownfield) conforme os planejamentos existentes. Por outro lado, uma baixa qualidade das juntas soldadas pode acarretar em acidentes envolvendo queda de vigas de grande peso e que podem causar perdas econômicas e humanas no canteiro de obras. Esta condição, 
oriunda de terceiros, já foi objeto de testemunho dos presentes autores, conforme o caso ilustrado na Figura 3.
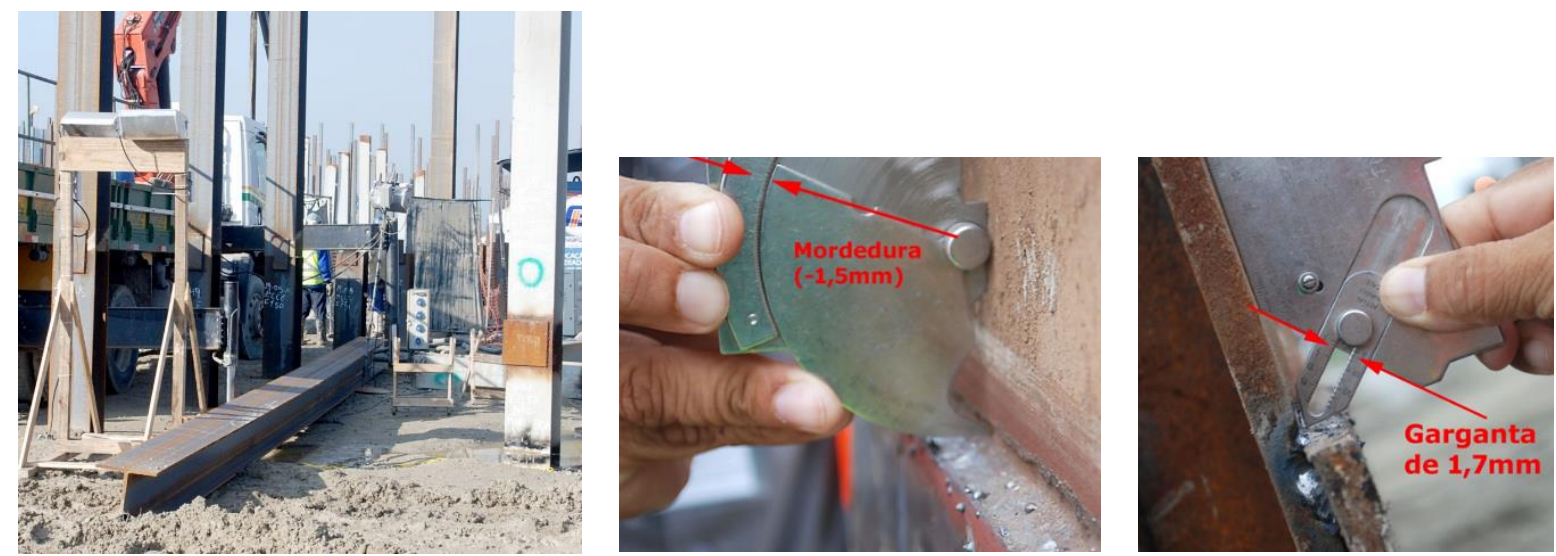

Figura 3. Caso de queda de viga durante operação

Neste trabalho, foram determinadas as atividades e tarefas de maior peso no Caminho Crítico (CC) do processo de cravação de estacas. Considerando o caso mais comum, no qual vigas de aço estrutural ASTM A572 Gr.50 [2] são unidas, com o emprego de talas, através da soldagem por eletrodo revestido (SMAW - Shielded Metal Arc Welding) [3], observou-se que esta atividade se tornava o gargalo da operação. Observando as características particulares do processo, verificou-se que a atuação nos procedimentos de execução da soldagem poderia reduzir seu tempo se execução, mantendo-se a confiabilidade e qualidade da emenda.

\section{MATERIAIS E MÉTODOS}

\subsection{União de Vigas para formar Estacas Metálicas}

A execução das uniões soldadas entre os perfis constituintes das estacas, pelo uso de talas soldadas a estes perfis (Fig. 2), é normatizado e deve ser dimensionado em conformidade com as condições de uso do material na obra. A norma NBR6122 [1] estabelece que as normas aplicáveis a esta operação são: NBR 8800 [4] e AWS D1.1 [5]. Em resumo, estas normas exigem que as soldas das emendas com talas devam atender aos seguintes requisitos:

1. seguir os preceitos do código AWS D1.1 [5];

2. apresentar qualidade adequada, conforme AWS D1.1 [5];

3. resistir aos esforços de uso normal das estacas, conforme NBR 8800 [4];

4. resistir aos esforços do manuseio/cravação, conforme AWS D1.1 [5].

Para o atendimento destas condições, as juntas soldadas devem ser executadas, conforme exemplificado pelo projeto da junta, calculado por um engenheiro mecânico, e pelas condições mandatórias do código AWS D1.1 [5], que exige:

1. evidência de qualificação de procedimento de soldagem (item 4.2.1);

2. aplicação de teste de qualificação para os soldadores (item 4.2.2);

3. armazenamento adequado dos consumíveis de solda (item 5.3.1.4 e 5.3.1.5); sendo que, para o caso de eletrodos revestidos:

a. secagem inicial/uso de eletrodos de baixo hidrogênio (item 5.3.2.1) em estufa entre 260 e $430^{\circ} \mathrm{C}$ por no mínimo 2 horas (item 5.3.2.4(1)); 
b. ressecamento de eletrodos expostos à atmosfera por um período além de 4 horas (item 5.3.2.2 e Tabela 5.1);

c. limitação de apenas um ressecamento (item 5.3.2.1).

4. limitação na quantidade de intensidade de descontinuidades/defeitos de solda (Tabela 6.1);

a. trincas (item 1 da Tabela 6.1);

b. falta de fusão entre metal base e solda (item 2 da Tabela 6.1);

c. geometria (perfil) do depósito de solda (item 4 da Tabela 6.1);

d. dimensões do depósito de solda (item 6 da Tabela 6.1);

e. 'mordeduras' na solda depositada (item 7(a) da Tabela 6.1);

f. porosidades na solda (item 8(a) da Tabela 6.1).

Conforme foi explicitado neste item, várias condições devem ser obedecidas para obter uma junta soldada, entre as vigas de obras de estaqueamento profundo. Nem todas as condições descritas são de pronto atendimento e algumas necessitam de uma infraestrutura mínima para serem efetivamente atendidas. Também é importante salientar que o material empregado nestas vigas, o aço ASTM A572 Gr.50 [2], é considerado de alta resistência mecânica conforme a norma NBR 6215 [5].

\subsection{Processo de União via Eletrodo Revestido (SMAW)}

A soldagem a arco elétrico com eletrodo revestido (Shielded Metal Arc Welding SMAW é o processo de soldagem mais empregado no país. Isso ocorre pela sua grande versatilidade, baixo custo de operação, simplicidade dos equipamentos e pela possibilidade de uso em locais de difícil acesso ou sujeitos a ventos [3].

Porém o processo SMAW apresenta algumas desvantagens, tais como: baixa produtividade, necessidade de cuidados especiais no tratamento e manuseio dos consumíveis (eletrodos revestidos) e o grande volume de gases e fumos gerados durante a soldagem. Conforme informações de um dos grandes fabricantes de consumíveis atuante no país, os eletrodos revestidos E7018 [6], empregados para o aço ASTM A572 Gr.50 [2], apresentam as seguintes características [7]:

1. são a versão mais moderna do eletrodo de baixo hidrogênio;

2. a quantidade considerável de pó de ferro no revestimento e também uma quantidade de revestimento bem maior permitem que esses eletrodos sejam aplicados sob correntes de soldagem mais altas que as empregadas com outros eletrodos, como o E7016 [6];

3. o arco mais suave e a facilidade de soldagem do eletrodo E7018 [6] tornamno o favorito dos soldadores;

4. correntes de soldagem relativamente mais altas e adições de pó de ferro fundindo no metal de solda para aumentar a taxa e eficiência de deposição;

5. o eletrodo básico E7018 [6] deposita o metal de solda de melhor qualidade para a soldagem de aços de baixo carbono;

6. sua maior desvantagem é que ele precisa ser mantido seco, eletrodos que absorveram umidade devido à exposição à atmosfera ou a outras fontes de umidade depositam metal de solda com porosidade;

7. os eletrodos E7018 [6] não devem ser aplicados na soldagem de passes de raiz em juntas de topo com abertura para evitar porosidade excessiva. 
As informações do fabricante [7] reforçam as solicitações obrigatórias do código AWS D1.1/D1.1M [5]:

1. consumíveis de soldagem que tenham sido removidos do pacote original devem ser protegidos e armazenados de tal forma que as propriedades de soldagem não sejam afetadas;

2. eletrodos devem estar secos e em condições apropriadas de uso;

3. eletrodos que tenham revestimentos de baixo hidrogênio (exemplo E7018 [6]) devem ser adquiridos em contêineres hermeticamente vedados ou devem ser cozidos (secos) adequadamente pelo usuário;

4. imediatamente após a abertura do contêiner hermeticamente vedado, os eletrodos devem ser armazenados em fornos mantidos a uma temperatura de pelo menos $250^{\circ} \mathrm{F}\left[120^{\circ} \mathrm{C}\right]$-isso normalmente é feito através de dispositivos semi-portáteis conhecidos como 'coxixos';

5. depois que contêineres dos eletrodos são abertos ou após eletrodos serem removidos de fornos de cozimento ou armazenamento, a exposição do eletrodo à atmosfera não deve exceder 4 horas;

6. eletrodos devem ser recozidos (ressecados) não mais que uma vez;

7. eletrodos que tenham sido molhados não devem ser usados.

\subsection{Características do processo de soldagem por Arame Tubular}

Sendo um processo de soldagem contínuo, os arames tubulares auto protegidos (self-shielded Flux-cored arc welding - FCAW-s) são capazes de atingir maiores taxas de deposição que os eletrodos revestidos, e são desenvolvidos para aplicações de soldagem em geral e aplicações específicas como reparos, soldagem fora de posição e soldagem de alta deposição.

Assim sendo, o processo de soldagem com arame tubular combina a produtividade de um processo contínuo de soldagem e os benefícios (protetivos e químicos) de um fluxo de solda presente, por isso, este processo apresenta várias vantagens relativas aos outros processos de soldagem, dentre as quais [8 e 9]:

- desenvolvidos e adequados para uso no campo para a soldagem de aços carbono em todas as posições e também para altas taxas de deposição;

- apresentam taxas de deposição maiores que a soldagem manual com eletrodos revestidos;

- não necessitam de equipamentos de solda especiais;

- geram cordões com boa aparência da solda, com aspecto limpo e escória facilmente removível;

- podem ser empregados na maioria dos aços estruturais com resistência mecânica da ordem de $510 \mathrm{MPa}$;

- apresentam as maiores taxas de deposição, especialmente em posições de solda não usuais;

- necessitam de menor necessidade de habilidade dos soldadores, menor do que nos processos de eletrodo revestido (SMAW) ou com gás protetivo (MIG/MAG);

- uma quantidade reduzida de respingos é outra vantagem frequentemente oferecida pelos arames tubulares;

- possuem maior tolerância à ferrugem e carepas de laminação (óxidos) do que os processos com gás protegido. 
O processo também apresentas duas características que podem limitar a sua aplicação em determinadas operações de soldagem 'indoor':

- necessidade de remoção de escória após a soldagem, que é similar ao caso do eletrodo revestido, porém com maior facilidade;

- maior geração de fumos de soldagem do que no processo de eletrodo revestido (pela maior velocidade e deposição);

- normalmente o processo de soldagem é empregado no campo, pois permite correntes de ar maiores.

A Figura 6 ilustra aplicações típicas para soldagem de estruturas de aço em ambientes abertos. Nestes casos, este processo apresenta o máximo ganho nas características anteriormente descritas.
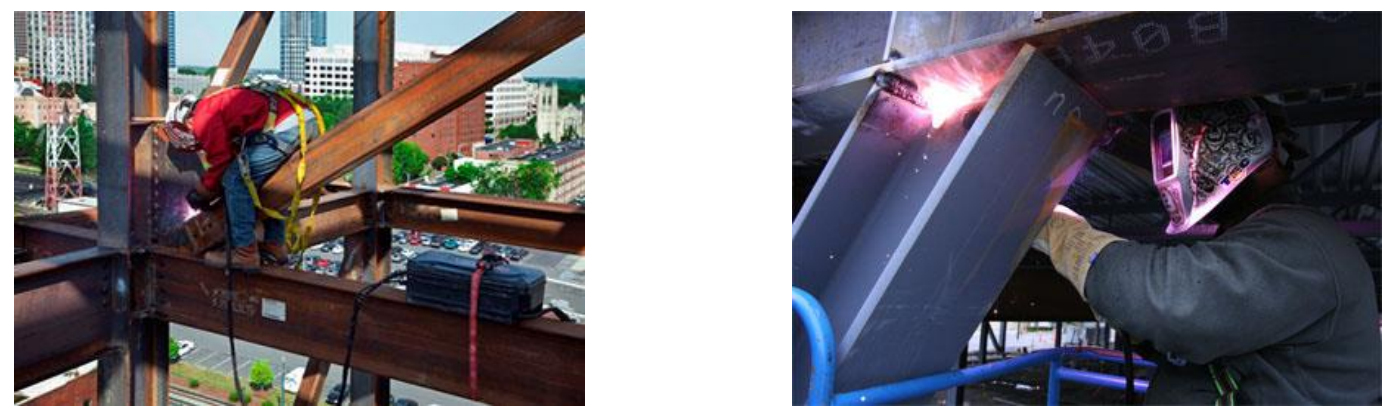

Figura 4. Possíveis aplicações do processo FCAW-s em operações de construção civil.

A soldagem por Arame Tubular auto protegido possui poucos requisitos em termos de equipamentos especiais. Dentre os equipamentos diferenciados a serem empregados, destaca-se a tocha FCAW-s, mostrada na Figura 5.
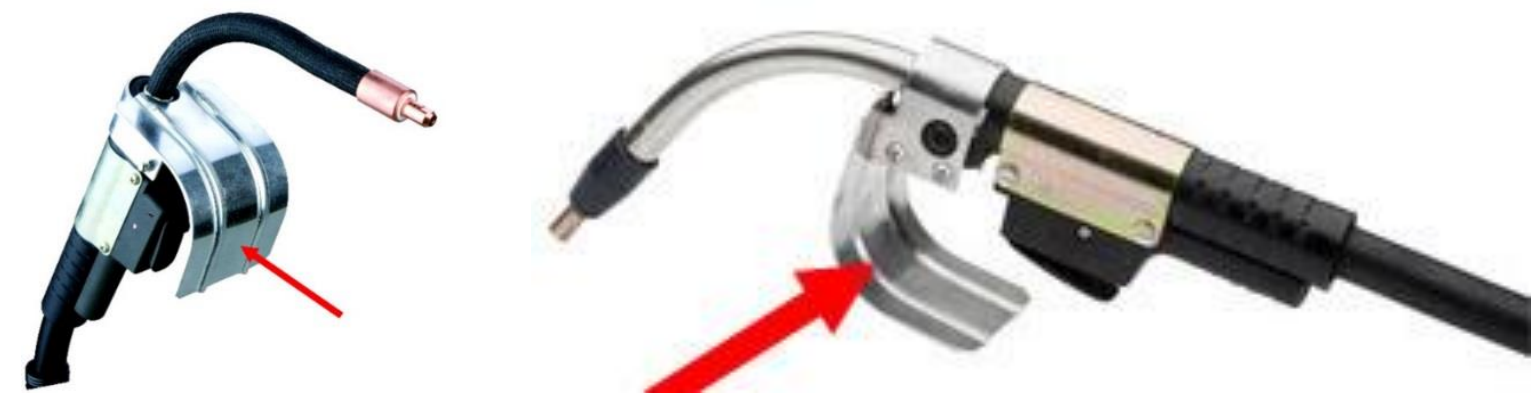

Figura 5. Aspecto da tocha de soldagem por Arame Tubular. O anteparo indicado pela seta serve para melhorar o conforto do soldador contra o arco elétrico que pode ficar aberto, depositando material, durante vários minutos.

Devido ao grande intervalo de tempo de arco aberto, a tocha possui uma proteção metálica que serve para refletir o calor emanado pelo processo de soldagem. Desta forma, a mão (enluvada) do soldador possui uma proteção adicional e assim melhoria de seu conforto da longa exposição ao arco, justamente pela alta produtividade do processo, que pode levar a manter o arco elétrico aberto, depositando solda, durante vários minutos. Outro acessório empregado é o alimentador do arame. Como o processo não necessita de gás de proteção, o arame pode ser armazenado em uma maleta (suitcase) que é ligada apenas à máquina de solda. O alimentador não apenas armazena e protege o rolo de arame, mas também controla a velocidade de alimentação e também a regulagem do equipamento de soldagem remoto. 
Embora existam processos de soldagem de maior produtividade disponíveis, tais como arco submerso e processos robotizados, o arame tubular auto protegido oferece ao usuário um processo mais flexível com aumentos reais em produtividade com um mínimo de capital investido. A migração de eletrodo revestido para arame tubular requer obviamente a aquisição de novos equipamentos, porém o indiscutível aumento em produtividade pode garantir o retorno do capital investido de tal forma que o maior preço dos consumíveis é geralmente compensado por uma economia muito maior no processo de soldagem como um todo.

\subsection{Comparações Laboratoriais}

Ao longo de um mês (Dez./2014) foram feitos inúmeros testes de desempenho do processo de arame tubular auto protegido (FCAW-S) nas instalações do Centro de Soldagem - INSPEBRAS ${ }^{\circledR}$. Estas experiências geraram importantes informações, especialmente para a comparação com o processo de eletrodo revestido (SMAW). Graças a estas atividades foi possível adequar equipamentos e procedimentos para serem empregados em testes de campo e assim obter os índices de produtividade finais. Em uma destas experiências, feita em caráter de demonstração, duas juntas de perfis estruturais de aço ASTM A572 Gr. 50 [2], foram soldadas simultaneamente: uma pelo processo de arame tubular auto protegido (FCAW-S) e a outra pelo processo com eletrodo revestido (SMAW) padrão empregado em uma obra em andamento na região portuária de Santos (ver item 2.5).

Soldadores reconhecidamente experientes foram selecionados para executar este teste que abrangeu todas as posições de soldagem que seriam empregadas na prática de união de perfis em estacas metálicas: 1G (plana), 2G (horizontal) e 3G (vertical), conforme ilustradas na Figura 6. Estiveram presentes representantes de empresas de região interessadas no potencial da técnica.

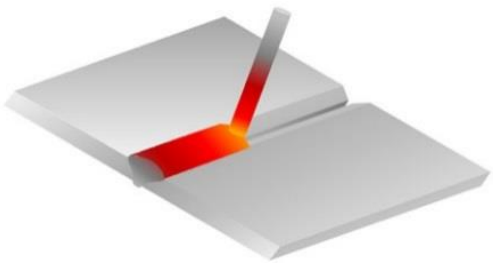

$1 \mathrm{G}$ (plana)

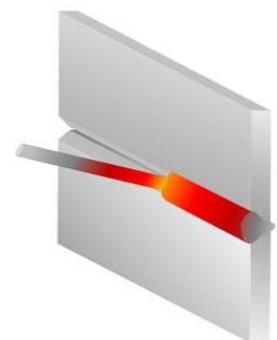

2G (horizontal)

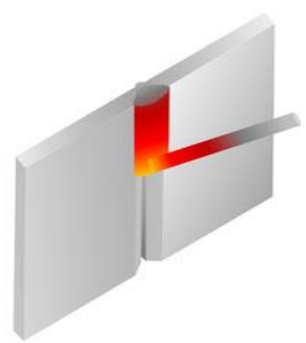

$3 G$ (vertical)

Figura 5. Posições de soldagem (padrão ASME [3 e 9]) empregadas na análise laboratorial.

Além desta experiência, uma análise comparativa de qualidade e de produtividade foi feita por alunos de Graduação em Engenharia Mecânica da UNISANTA. Estes alunos desenvolveram um trabalho de TCC [11] comparando diretamente os processos SMAW e FCAW-s na soldagem de vigas de aço ASTM A572 Gr.50 [2] em condições similares às encontradas na prática das fundações profundas.

\subsection{Testes de Campo}

O emprego do processo FCAW-s foi primeiramente implementado nas obras de expansão do TIPLAM (Terminal Integrador Portuário Luiz Antonio Mesquita). Este terminal, que está localizado no Município de Santos (SP) e ao lado da UsiminasCubatão (ex COSIPA), está sendo ampliado para aumentar a capacidade de 
recebimento de matérias-primas, para a produção de fertilizantes, e para a exportação competitiva de granulados, especialmente açúcar, soja e seus derivados. Neste primeiro local foram aperfeiçoadas as novas técnicas selecionadas para o processo. Porém outras alterações foram avaliadas e implementadas de forma a reduzir o tempo gasto no caminho crítico do processo como um todo. Algumas das soluções foram: tendas à prova de escorrimento de água de chuva (pelos perfis); suportes de talas para ponteamento, uso de corte a plasma manual para obter talas e fazer o nivelamento ('arrasamento') dos perfis já cravados.

Após a incorporação do processo $F C A W$-s e das demais soluções desenvolvidas e empregadas para a obra portuária em Santos, as soluções foram agrupadas em torno da marca INO///FAST ${ }^{\circledR}$ e passaram a ser empregadas em duas outras obras de fundações profundas no país:

1. Expansão da Bio Manguinhos - unidade da FIOCRUZ que responde pela pesquisa e fabricação de vacinas, que será responsável, dentre outras coisas, pelo fornecimento da maioria das vacinas essenciais para o calendário básico de imunização do Ministério da Saúde brasileiro.

2. Consórcio Mobilidade Bahia - expansão da rede metroviária da região metropolitana de Salvador que ligará a capital da Bahia à cidade de Lauro de Freitas, serão mais 21,2 quilômetros de extensão com 12 estações e tem conclusão prevista para 2017.

\section{RESULTADOS E DISCUSSÃO}

As fotos apresentadas na Figura 6 foram obtidas diretamente da filmagem completa de uma comparação direta e simples entre os processos SMAW e FCAW-s. Estas fotos ilustram as diferenças de velocidade e de intensidade de energia envolvida nos processos de Eletrodo Revestido e arame tubular auto protegido.

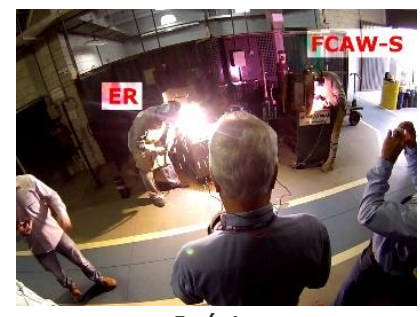

Início

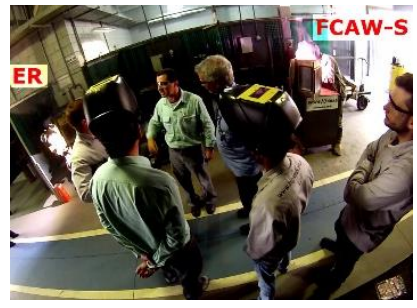

34 minutos

(término do FCAW-S)

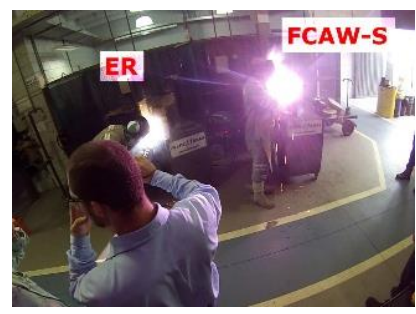

17 minutos

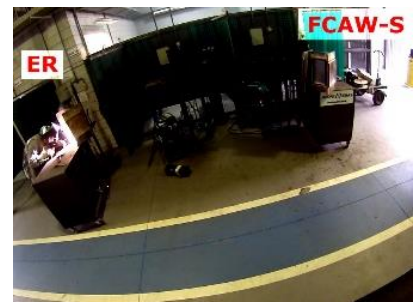

50 minutos (somente o ER)

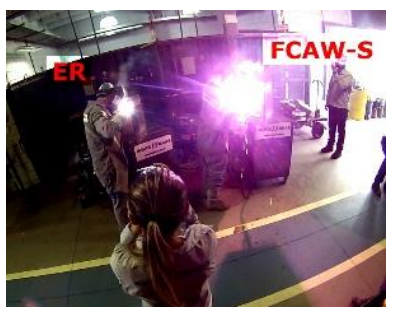

23 minutos

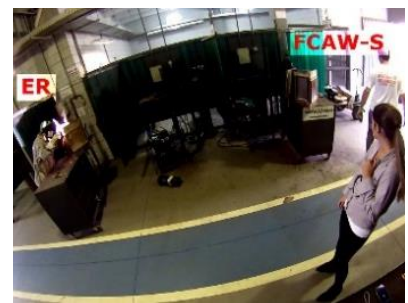

60 minutos

(término do ER)

Figura 6. Compilação da simulação da execução de uma junta soldada de vigas de aço estrutural ASTM A572 Gr.50 [2] através dos processos SMAW e FCAW-S, realizadas na INSPE///BRAS ${ }^{\circledR}$.

Como resultado final destes testes, obteve-se duas informações relevantes:

1. A duração do processo de execução da emenda foi de 34 minutos para o processo FCAW-s e de 60 minutos para o processo SMAW (43\% mais rápido). 
2. A quantidade de metal depositado pelo processo SMAW, para as condições de execução do teste foi da ordem de $6 \mathrm{~mm}$ (perna de solda) enquanto que 0 FCAW-s depositou cerca de $10 \mathrm{~mm}$ (67\% mais metal).

Estes resultados indicam o processo $F C A W$-s especificado é 2,94 vezes mais rápido do que o processo SMAW empregado e referenciado nesta experiência. Os fatores relacionados à produtividade indicam vantagem na aplicação do arame tubular, devido à sua velocidade de operação.

Em termos de velocidade de execução, o Trabalho de Conclusão de Curso (TCC) efetuado pelos alunos da UNISANTA [11] apontou uma velocidade similar à obtida na experiência ilustrada na Figura 6 . A Tabela 2 apresenta um resumo dos dados obtidos neste trabalho [11] e a partir dos quais pode-se notar uma taxa de deposição e velocidade maiores $33 \%$ a $54 \%$ (em média) no processo $F C A W$-s selecionado em relação ao SMAW padrão. No caso deste trabalho [11], as experiências foram realizadas em uma junta por posição (2G, 3G e $4 \mathrm{G})$ e a análise da produtividade não poderia ser baseada apenas na velocidade de deposição para este cenário, que é muito conservador, já que não considera as diferenças de manuseio dos insumos e na dinâmica da execução de um processo descontínuo (SMAW) em relação a um processo contínuo (FCAW-s).

Tabela 1. Resultados numéricos das experiências comparativas [11]

\begin{tabular}{|c|c|c|c|c|c|c|}
\hline \multirow{2}{*}{ Variável } & \multicolumn{3}{|c|}{ SMAW } & \multicolumn{3}{|c|}{ FCAW-s } \\
\hline & 2G & 4G & 2G/3G & 2G & 4G & 2G/3G \\
\hline Tamanho da ZTA (mm) & 2,9 & 2,1 & 2,2 & 2,3 & 2,6 & 1,8 \\
\hline Temperatura da ZTA (mm) & 245 & 425 & 400 & 250 & 400 & 350 \\
\hline Dureza média metal base & 80 & 81 & 80 & 90 & 81 & 80 \\
\hline Dureza média metal de adição & 92 & 90 & 92 & 92 & 90 & 92 \\
\hline Dureza média ZTA & 89 & 90 & 89 & 89 & 90 & 89 \\
\hline Resistência à tração (MPa) & 260 & 250 & 265 & 210 & 250 & 350 \\
\hline Aporte térmico $(\mathrm{KJ} / \mathrm{mm})$ & 10,5 & 7,47 & 7,23 & 5,84 & 7,20 & 5,20 \\
\hline Metal depositado (g/min.) & 21,03 & 18,72 & 16,14 & 34,04 & 27,94 & 35,32 \\
\hline
\end{tabular}

Durante a participação nas obras de expansão do TIPLAM, inúmeras soluções adicionais foram planejadas e posteriormente implementadas analisando-se 0 processo melhorado pelo uso da soldagem FCAW-s. Em todos os casos, o objetivo foi empregar o Método do Caminho Crítico para determinar etapas ou operações que criassem 'gargalos' na produção de modo a substituí-los por operações mais enxutas e produtivas. A Figura 7 ilustra dois exemplos de práticas adotadas que incrementaram ainda mais a produtividade em campo:

1. linha de preparação de perfis, tipo Pipe shop - instalação metalúrgica de canteiro para fabricação de estruturas metálicas, suportes, tubulações, etc.

2. dispositivos de posicionamento e alinhamento de talas para ponteamento facilitado.

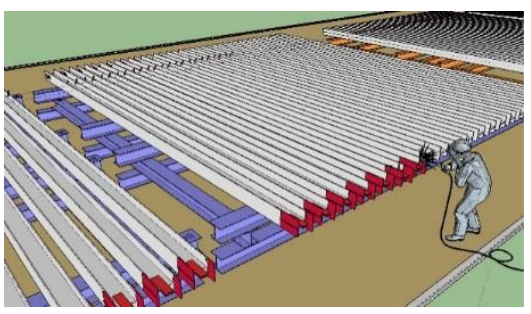

Linha de preparação dos perfis.

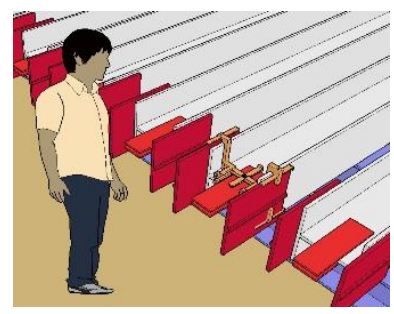

Dispositivo de posicionamento de talas. 
Figura 7. Algumas soluções empregadas em conjunto com o processo FCAW-s para aumentar a produtividade da execução de obras de fundações.

Após o primeiro teste de campo, o conjunto de técnicas de execução de emendas em estacas metálicas foram agrupadas ao redor do nome INO///FAST $^{\circledR}$, que está sendo empregado em outras frentes de obras. A Tabela 2 apresenta os últimos resultados comparativos obtidos em campo, entre o INO///FAST ${ }^{\circledR}$ e os processos padrão, empregados por empresas "A" e "B", através da soldagem SMAW, sem as soluções desenvolvidas neste trabalho.

Tabela 2. Resultados práticos da aplicação das soluções desenvolvidas em obras práticas.

\begin{tabular}{rcccccc}
\hline & \multicolumn{3}{c}{ Desde o início dos trabalhos } & \multicolumn{3}{c}{ Mês de Abril de 2016 } \\
\hline & A & B & INO///FAST & A & B & INO///FAST $^{\oplus}$ \\
\hline Total de emendas & 499 & 852 & 1206 & 18 & 88 & 243 \\
Meses trabalhados & 7 & 7 & 4 & 1 & 1 & 1 \\
Número de soldadores & 6 & 13,5 & 3 & 6 & 13,5 & 3 \\
$\begin{array}{r}\text { Produtividade } \\
\text { (emenda/soldador.mês) }\end{array}$ & 11,9 & 9,0 & 100,5 & 3,0 & 6,5 & 81,0 \\
\hline
\end{tabular}

Pelo apresentado na Tabela 2, a produtividade em termos de uniões (emendas) entre dois perfis estruturais em relação à quantidade de soldadores empregados ao longo de um mês é no mínimo de 8 (oito) vezes maior (ou 700\%), tendo uma média de 10.

\section{CONCLUSÃO}

A necessidade do mercado na execução de uniões em vigas para fundações profundas estimulou a INSPE///BRAS a buscar soluções para esta aplicação. Após pesquisas inicias realizadas no CENTRO DE SOLDAGEM - INSPE///BRAS e apresentadas aos seus clientes apontaram uma produtividade teórica 3 vezes superior aos processos tradicionais no mercado. Ao longo do processo, os ganhos de produtividade foram melhorados reduzindo-se o tempo das atividades que compõem o caminho crítico do processo de forma que atualmente obteve-se um ganho de produtividade 8 (oito) vezes maior em relação aos processos tradicionais.

\section{REFERÊNCIAS}

1 ABNT NBR 6122:1996. Projeto e execução de fundações, ASSOCIAÇÃO BRASILEIRA DE NORMAS TÉCNICAS, 1996.

2 ASTM A572/A572M:15. Standard Specification for High-Strength Low-Alloy ColumbiumVanadium Structural Steel, AMERICAN SOCIETY FOR TESTING AND MATERIALS, 2015. MODENESI, Paulo J.; MARQUES, Paulo Villani; BRACARENSE, Alexandre Q. Soldagem Fundamentos e Tecnologia. Universidade Federal de Minas Gerais. Departamento de Engenharia Metalúrgica. Belo Horizonte, 2007.

4 ABNT NBR 8800:2008. Projeto de estruturas de aço e de estruturas mistas de aço e concreto de edifícios, ASSOCIAÇÃO BRASILEIRA DE NORMAS TÉCNICAS, 2008.

5 AWS D1.1/D.1.1M. Structural Welding Code - Steel (Approved as American National Standard), AMERICAN WELDING SOCIETY, 2010.

6 AWS A5.1/A5.1M. Specification for Carbon Steel Electrodes for Shielded Metal Arc Welding. AMERICAN WELDING SOCIETY, 2004.

7 FORTES, C. VAZ, C.T. Apostila de Eletrodos Revestidos. ESAB. 2005. 
8 ASME Sec. II, Part C. SFA-5.20/SFA-5.20M. Specification for carbon steel electrodes for flux cored arc welding, AMERICAN SOCIETY OF MECHANICAL ENGINEERS, 2010.

9 ASM Handbook Volume 06: Welding, Brazing and Soldering, vol. 06, Materials Park, 1993. ABNT NBR 6215:2011. Produtos siderúrgicos - Terminologia, ASSOCIAÇÃO BRASILEIRA DE NORMAS TÉCNICAS, 2011.

10 ABNT NBR 6215:2011. Produtos siderúrgicos - Terminologia, ASSOCIAÇÃO BRASILEIRA DE NORMAS TÉCNICAS, 2011.

11 SOUZA, G.R. et. al. Soldagem com Eletrodo Tubular Autoprotegido FCAW-s para Aços

Estruturais Empregados em Elementos da Construção Civil. Monografia de TCC. Unisanta, Dez. 2015 